\title{
O INSTANTE DECISIVO DE HENRI CARTIER-BRESSON E A INDEXAÇÃO: UM ESTUDO EXPLORATÓRIO DE MÉTODOS DE INDEXAÇÃO DE FOTOGRAFIAS
}

\author{
HENRI CARTIER-BRESSON'S DECISIVE INSTANTE AND INDEXATION:
} AN EXPLORATORY STUDY OF METHODS OF INDEXING PHOTOGRAPHS

EL INSTANTE DECISIVO DE HENRI CARTIER-BRESSON Y LA INDEXACIÓN: UN ESTUDIO EXPLORATORIO DE MÉTODOS DE INDEXACIÓN DE FOTOGRAFÍAS

\footnotetext{
Welington Rodrigo Zanon, ${ }^{1}$ Deise Maria Antonio Sabbag

${ }^{1}$ Universidade de São Paulo
}

\section{Correspondência}

'Welington Rodrigo Zanon Universidade de São Paulo São Paulo, SP

Email: wellzanon@hotmail.com ORCID:

Submetido em: 18-04-2017

Aceito em: 15-07-2017

Publicado: 08-08-2017

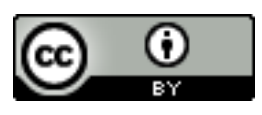

JITA: IC. Index languages, processes and schemes. 
RESUMO: A pesquisa aborda métodos de indexação de fotografias na perspectiva da representação dos trabalhos de Henri Cartier Bresson e o instante decisivo. Tem caráter exploratório e descritivo, sob uma abordagem qualitativa, utilizando procedimentos de pesquisa documental, levantamento e análise de conteúdo. A pesquisa valeu-se pelo método de classificação e indexação, de acordo com técnicas de experimentação, onde o conteúdo é avaliado de acordo com sentido conotativo da imagem. Buscou-se o melhor método de indexação para as fotografias de Henri Cartier-Bresson, a fim de extrairmos o maior número de informações possíveis da representação visual do documento (fotografias), e minimizar as perdas nesta transcrição. Para tanto, utilizamos os quatro métodos de indexação de fotografias desenvolvidos pelos autores Panofsky (1986), Smit (1986), Manini (2002) e Rodrigues (2007), aplicando-os a (03) fotografias de Bresson. Após a aplicação realizou-se análise comparativa e discussão dos resultados.

PALAVRAS-ChAVE: Ciência da Informação. Fotografia. Indexação. Análise documental

ABSTRACT:The research presents methods of indexing photographs from the perspective of Henri Cartier Bresson 's work and the decisive instant. The methodology of the work is exploratory and descriptive, with a qualitative approach, using documental research procedures, survey and content analysis. The research was based on the method of classification and indexing by studying the best indexing method for the photographs of Henri Cartier-Bresson, in order to extract as much information as possible from the visual representation of the document (photographs), and to minimize the losses in this transcription. For this, we used the four methods of indexing of photographs developed by the authors Panofsky (1986), Smit (1986), Manini (2002) and Rodrigues (2007), applying them to three (03) Bresson photographs. After the application, we performed a comparative analysis and discussion of the results.ords at maximum.

KEYWORDS: Informacion Science. Photography. Indexing. Documentary analysis.

RESUMEN: La investigación aborda métodos de indexación de fotografías en la perspectiva de la representación de los trabajos de Henri Cartier Bresson y el instante decisivo. Tiene carácter exploratorio y descriptivo, bajo un enfoque cualitativo, utilizando procedimientos de investigación documental, levantamiento y análisis de contenido. La investigación se valió por el método de clasificación e indexación, de acuerdo con técnicas de experimentación, donde el contenido es evaluado de acuerdo con sentido connotativo de la imagen. Se buscó cuál es el mejor método de indexación para las fotografías de Henri Cartier-Bresson, a fin de extraer el mayor número de informaciones posibles de la representación visual del documento (fotografías), y minimizar las pérdidas en esta transcripción. Para ello, utilizamos los cuatro métodos de indexación de fotografías desarrollados por los autores Panofsky (1986), Smit (1986), Manini (2002) y Rodrigues (2007), aplicando a (03) fotografías de Bresson. Después de la aplicación se realizó análisis comparativo y discusión de los resultados.

PALAVRAS-ClavE: Ciencia de la información. Fotografía. Indización. Análisis documental 


\section{A FOTOGRAFIA EM CONTEXTO HISTÓRICO}

O século XIX ficou conhecido como o século dos inventores. Várias foram as contribuições deste período que influenciaram nossa sociedade moderna sendo que estas invenções, com o passar do tempo, fizeram parte da nossa comunicação influenciando a forma como vemos e nos relacionamos com mundo. A fotografia teve um papel fundamental na constituição da memória através da imagem, uma vez que proporcionava, em sua essência, o registro de cenas do cotidiano, bem como da história moderna. Podemos ir além ao dizer que a sociedade no seu caminhar tinha por necessidade registrar os acontecimentos, mesmo que precariamente. Corrobora com essa ideia Kossoy (1999) quando diz que: "a expressão cultural dos povos exteriorizada através dos seus costumes, habitação, monumentos, mitos e religião, fatos sociais e políticos passou a ser gradativamente registrados pela câmera" (KOSSOY, 1999, p. 26). Era o início de um método de aprendizado, onde o real parecia ser mostrado através das lentes de uma máquina. Os fragmentos da sociedade e das coisas eram codificados através da representação dos objetos e fatos cotidianos como constatações de uma realidade que poderia ser guardada para a posteridade.

$\mathrm{Na}$ perspectiva de posteridade, Bazin (1991) procura mostrar que existia uma necessidade conceitual em recriar, através dos registros fotográficos, uma forma de vencer o perecimento da matéria através da perenidade da forma, utilizando-se o recurso da semelhança, para se contar determinados acontecimentos. Couchot (1999) descreve que a fotografia era dotada de uma alma, uma miniatura de realidade, onde implica sempre a presença de um objeto preexistente à imagem. Susan Sontag (1981) descreve um sujeito e um objeto presentes na apropriação da fotografia, pois: "fotografar é apropriar-se da coisa fotografada. É envolver-se em uma certa relação com o mundo que se assemelha com o conhecimento - e, por conseguinte com o poder" (SONTAG, 1981, p.4).

Pela consideração de um registro do mundo fragmentado, a fotografia possui o aspecto comprobatório dos acontecimentos graças ao seu caráter testemunhal dos fatos. A história parecia ganhar um documento que comprova a existência das coisas, e de certa forma, o fazia com uma certa propriedade a partir destes registros. "Os fatores intrínsecos aos desdobramentos da memória estavam presentes nos objetos fotografados e revelados, bem como sua documentação histórica" (MOREIRA, 1993 p. 17). A fotografia é como uma tela em branco que através daquele instante pudesse ser interpretada pelo interlocutor. Desta forma, se aproxima do caráter artístico, pois a fotografia consegue imprimir sentimentos naqueles que a veem, capacidade também presente na pintura.

Por outro lado, uma característica distintiva entre fotografia e pintura é que na fotografia se evidencia um fato pela captura do momento. A subjetividade presente na fotografia toma forma através do conceito de instante decisivo de Cartier-Bresson. Uma ação 
metonímica da realidade em que o registro foi feito através da câmera fotográfica, em seu momento mais preciso, e que busca de alguma forma, se comunicar com o expectador. Característica ausente na pintura ou em outras expressões artísticas pelo uso de um objeto.

Bresson aproxima a fotografia da arte como forma de expressão fazendo um comparativo entre ambas, e cita: "Nós, talvez por atingirmos uma coisa bem menos permanente do que os pintores, por que haveríamos de nos sentir incomodados? Em vez disso, até achamos divertido, pois através da nossa máquina fotográfica, nós aceitamos a vida em toda a sua realidade" (CARTIER-BRESSON, 2004, p. 22)

A fotografia, por outro lado, não precisa necessariamente trazer mensagem alguma quando a imagem tem um caráter mais visual do que teórico. Às vezes a beleza da imagem já lhe basta, e isso não faz com que a memória daquele momento seja desvalorizada ou perca seu caráter de registro fotográfico. Apenas é uma outra abordagem sobre ela que não a atribui um caráter menor.

\section{FOTOGRAFIA: HISTÓRIA OU MEMÓRIA}

De acordo com o dicionário Michaelis (2015), memória é a faculdade de lembrar e conservar ideias, imagens, impressões, conhecimentos e experiências adquiridas no passado e habilidade de acessar essas informações na mente. A fotografia é algo que representa fatos históricos ou de memória. Pegamos uma foto do século passado, por exemplo, onde não tivemos essa experiência sensorial e podemos representa-la. Bem como uma foto tirada quando éramos crianças que nos desperta lembranças. A fotografia tem a posse de memória, sejam elas individuais e coletivas. Através destes fragmentos de realidade registrados pelo fotógrafo, ou através do seu olhar pela câmera, podemos nos inserir no universo fotografado; afim de criarmos uma realidade própria.

Henri Cartier-Bresson (1908-2004), grande fotógrafo, considerado por muitos como o pai do fotojornalismo, por meio de seus registros, durante quase um século de atuação no campo da fotografia, apresenta seu trabalho imagens, objetos, cenas e pessoas que nos ajudam a entender sua percepção do mundo que registrava através de seu olhar. "Assim como Picasso é para as artes plásticas, Bresson pode ser considerado para a fotografia" (SANTANA, [2016?], Web), desta forma, percebemos sua influência no campo fotográfico, ao dizer:

“[...] de todos os meios de expressão, a fotografia é o único que fixa para sempre o instante preciso e transitório. Nós, fotógrafos, lidamos com coisas que estão continuamente desaparecendo e, uma vez desaparecidas, não há nenhum esforço sobre a terra que possa fazê-la voltar. Não podemos revelar ou copiar uma memória. (CARTIER-BRESSON, 1971, p. 21). 
Percebemos que existe na fotografia a propriedade de inserir à imagem em um contexto que vai além da própria imagem. O processo de registro fotográfico é constituído por fotógrafo, câmera, olhar do fotógrafo, instante em que é registrada e, por fim, a fotografia. Um instante pode mudar o contexto do registro. O papel do fotógrafo é estar atento ao que será registrado, pois o enquadramento possível de realidade entre vários outros podem mudar em fração de segundos.

Jacques Le Goff (2003), em seu livro História e Memória, defende a memória como uma propriedade de conservar certas informações; propriedade esta que se refere à um conjunto de funções psíquicas que permitem ao indivíduo atualizar impressões ou informações passadas, ou reinterpretadas como passadas. Desta forma, exclui qualquer tipo de manipulação feita nessas fotografias a fim de alterar qualquer caráter de memória a ela atribuída, e é neste contexto que nos atentaremos para legitimar a importância da fotografia na construção da memória coletiva e seus desdobramentos sociais.

Várias são as ciências que estudam a memória de acordo com contextos diferentes. Podemos citar a Psicologia, Sociologia, Neurofísica, dentre outras, porém um consenso geral entre seus significados é a capacidade que a memória social tem em abordar as questões pertinentes sobre o tempo e a história.

Sob essa perspectiva é importante ressaltar que existem vários conceitos que tratam a memória. Neste artigo nos aproximamos das ciências que incluem a memória de acordo com interpretações sociais de tempo e espaço, pois assim conseguiremos apresentar argumentos que nos explique a importância da memória coletiva, ou compartilhada, no que se refere à disseminação de informações, e da memória individual ao interpretar a polissemia da imagem. Lembrando que, memória individual é aquela que cada indivíduo guarda dos acontecimentos vivenciados. Nosso foco é a memória coletiva, ou seja, registrada e compartilhada, traçando um paralelo com a memória individual ao interpretar acontecimentos que só farão sentido ao expectador de determinada fotografia.

\section{O INSTANTE DECISIVO: HENRI CARTIER-BRESSON}

Nascido na França em 22 de agosto de 1908, não faltam adjetivos para qualificar a trajetória profissional do fotógrafo Henri Cartier-Bresson. Foi o pioneiro em ensinar por meio da arte da fotografia como capturar a magia do momento em suas viagens através do mundo. Sempre com uma Leica na mão, suas fotos registravam sua forma de ver a vida em preto e branco.

Considerava fotografar uma arte, e desta forma conseguia traduzir em poesia o que via por detrás da câmera. Se expressava de forma leve, sem limites. Introduziu a leveza no 
fotojornalismo, congelando o momento ideal de uma imagem que jamais se repetiria. Separa o conteúdo da forma, e depois o complementa de forma harmoniosa através da retratação de sua mensagem, como descreve Cartier-Bresson (2004), ao dizer que uma fotografia é para ele o reconhecimento simultâneo numa fração de segundos: por um lado uma significação de fatos e por outro, uma organização rigorosa das formas percebidas visualmente que exprimem estes fatos.

Criou o termo, O Instante Decisivo, a partir de uma foto de Martin Munkacsi (1930), tirada no congo. Se inspirou ao perceber que existia na fotografia um algo mais que ia além da beleza plástica da foto. Na foto, publicada pela revista Photographies em 1931, o inspirador, registrou três crianças correndo para o mar, perseguindo a liberdade, com uma leveza genuína e subjetiva, através de um momento mágico e único. A beleza plástica da foto foi o estopim para a carreira de Bresson, pois aquela reunião de elementos estéticos e poéticos, alinhada à realidade da vida. Esta imagem impulsionou sua carreira como fotógrafo e mais além iria revolucionar o conceito de fotojornalismo ao congelar o momento exato do clique.

Essa obsessão em perseguir esse momento singular tornou-se uma característica que o perseguira desde então.

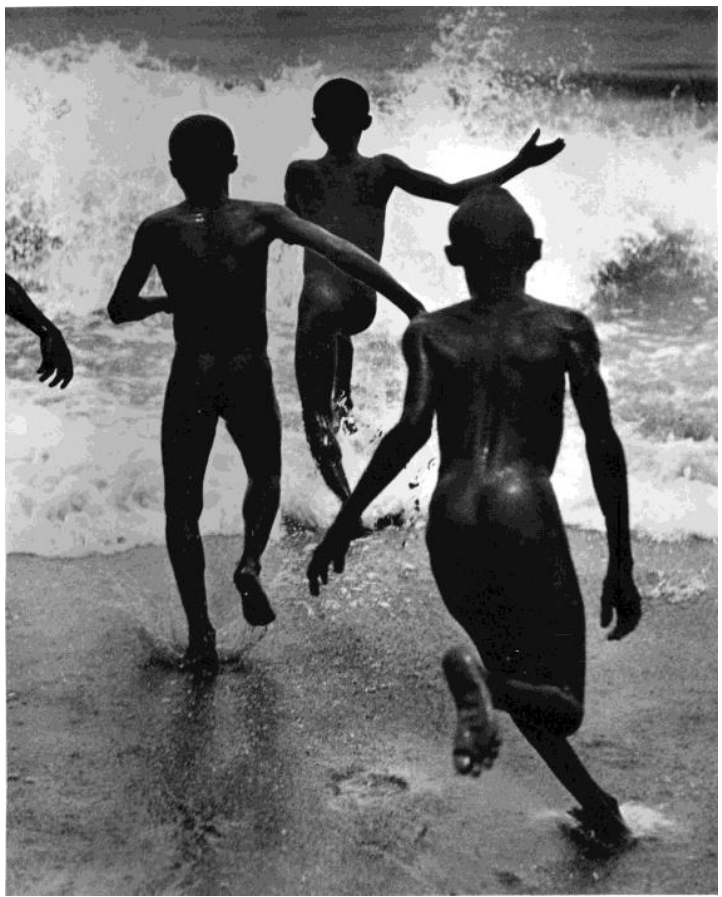

Fotografia 1. Boys running into the surf at lake Tanganyika Fonte: Associação Portuguesa de Photographia, 2007

Segundo o conceito de Cartier-Bresson (2004), a fotografia tem um instante exato para se alinhar com o olhar do fotógrafo. Esses momentos são fugazes, e por esse motivo é necessário esperar o momento certo para que ela consiga se traduzir e desta forma coloca-la 
na mesma mira a cabeça, o olho e a emoção. O termo "O instante decisivo" representa o momento exato em que a imagem se transforma em uma portadora da linguagem com toda sua plenitude. Algo que representa não somente a beleza plástica da foto, mas sim, o que traz consigo a representação metalinguística da cena. A fotografia conversa com o artista da mesma forma que sua representação conversa com o expectador, dando uma continuidade no sentido através daquela fração de segundos. Caso escape o momento, este não pode mais ser capturado sob essa tradução. Tradução daquilo que sentimos e algumas vezes não conseguimos representar através do uso de palavras, mas sim através do olhar e do sentido.

Cartier-Bresson (2004) reafirma sua teoria ao dizer que em fotografia há uma plástica nova, uma função de linhas instantâneas; nós trabalhamos no movimento uma espécie de pressentimento da vida, e que a fotografia deve captar no movimento o equilíbrio expressivo.

Nesta citação de Bresson percebemos um desdobramento onde todos os elementos contidos entre o olhar do fotógrafo, o objeto fotografado e o trabalho revelado passam pelas lentes por uma fração de segundos perpetuando-se através do momento ideal. Isso se dá quando a espera do fotógrafo é traduzida e pode ser decodificada pelo expectador quando se traduz o equilíbrio entre todos esses elementos. A subjetividade do momento oportuno se eterniza com toda sua beleza em composição e contrastes de luz e sombra e, desta forma, determina uma boa e uma má fotografia. Chalhub (2002), descreve essa subjetividade ao dizer que "uma foto pode estar contaminada com traços poéticos, uma roupa pode coordenar na sua montagem sintagmática, o equilíbrio de cor e textura do tecido; um prato de comida pode desenhar sensualmente a forma e o cheiro do cardápio" (CHALHUB, 2002, p. 30).

Segue abaixo mais uma das fotos de Cartier-Bresson, dentre várias, carregadas de simbolismos que evidenciam o conceito criado por ele de Instante decisivo, carregam consigo uma carga semântica que serão mais adiante neste trabalho experimentadas de forma a preservar o conteúdo de seus elementos implícitos. 


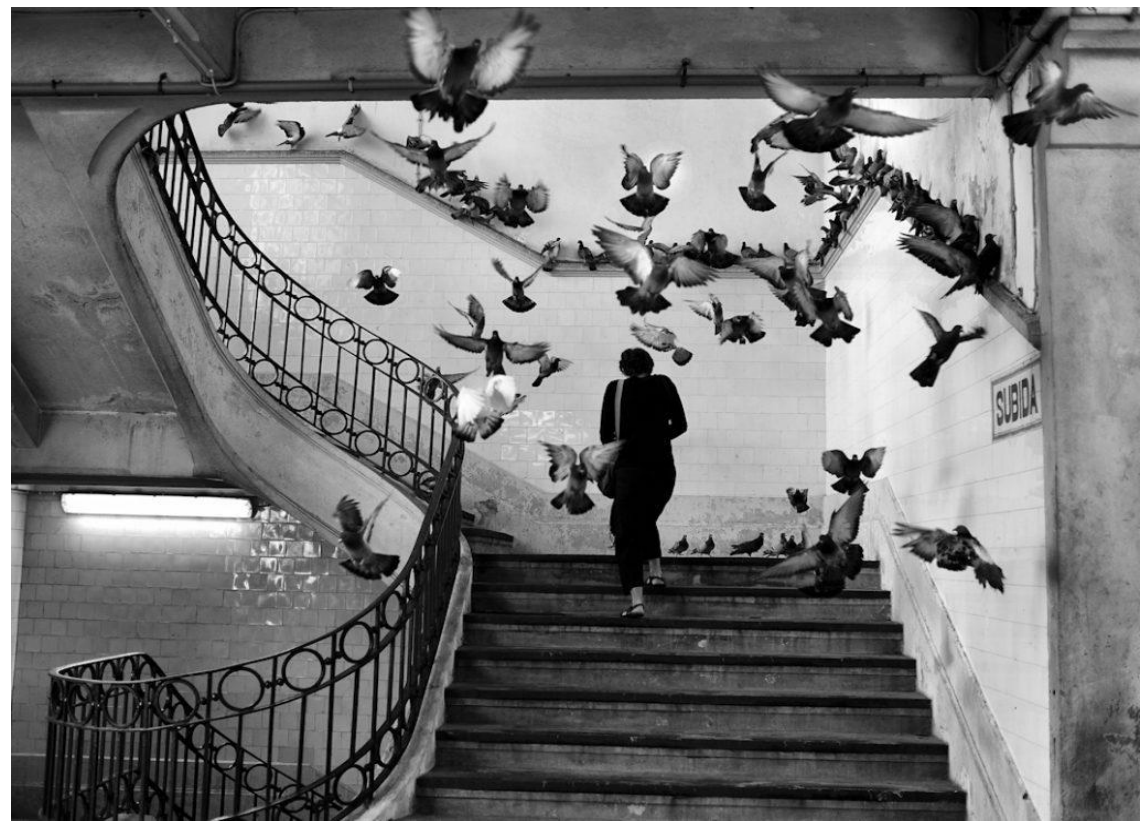

Fotografia 2. Revoada dos Pombos

Fonte: https://goo.gl/bGAzPD

Selecionamos para análise três de suas fotos. Assim, temos:

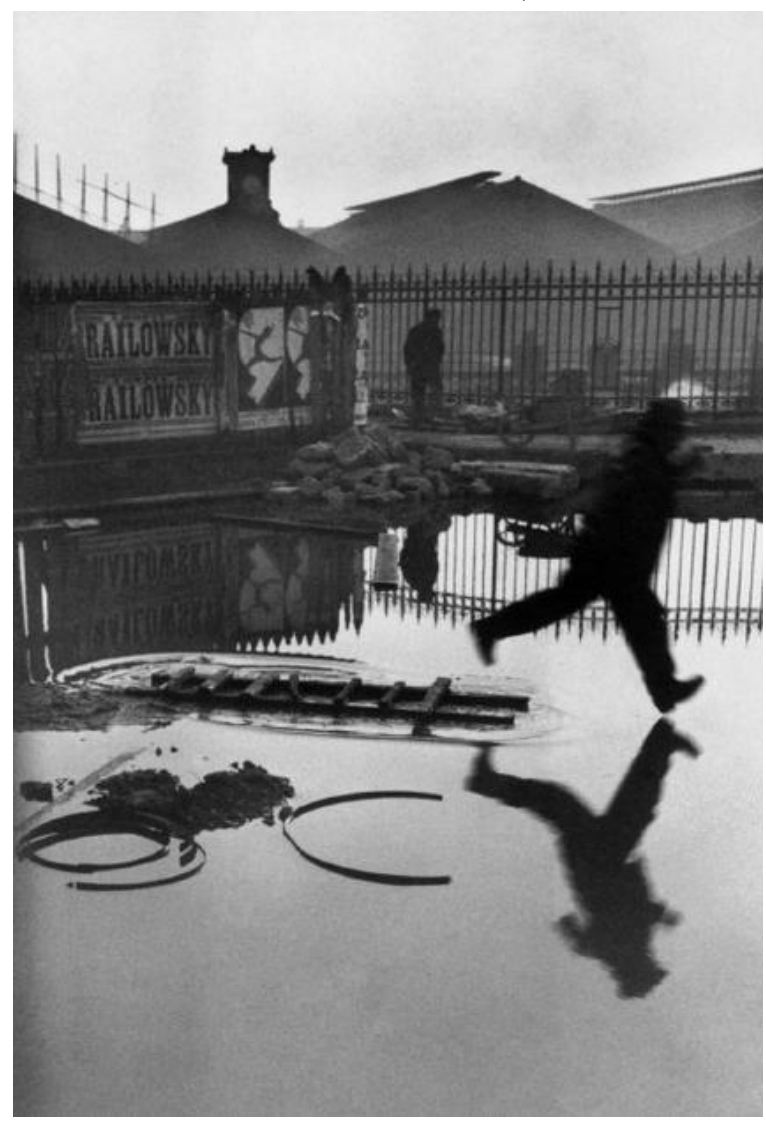

Fotografia 3. Gare St Lazare, Paris, 1932

Fonte: Henri..., sd. 
A fotografia retrata a perfeita harmonia entre o objeto (homem) e sua sombra. Uma geometria perfeita, contrastando com o fundo (segundo plano), sua respectiva sombra e a escada. A foto caracteriza-se pela fluidez dos movimentos do personagem principal. A impressão é que ele está bailando no ar, sem o apoio dos pés no chão. Em outro instante que o próximo passo é de se fundir com água desarranjando sua forma geométrica ao ser absorvido pela sua sombra.

Outra fotografia selecionada para esta análise é a do piquenique às margens do rio.

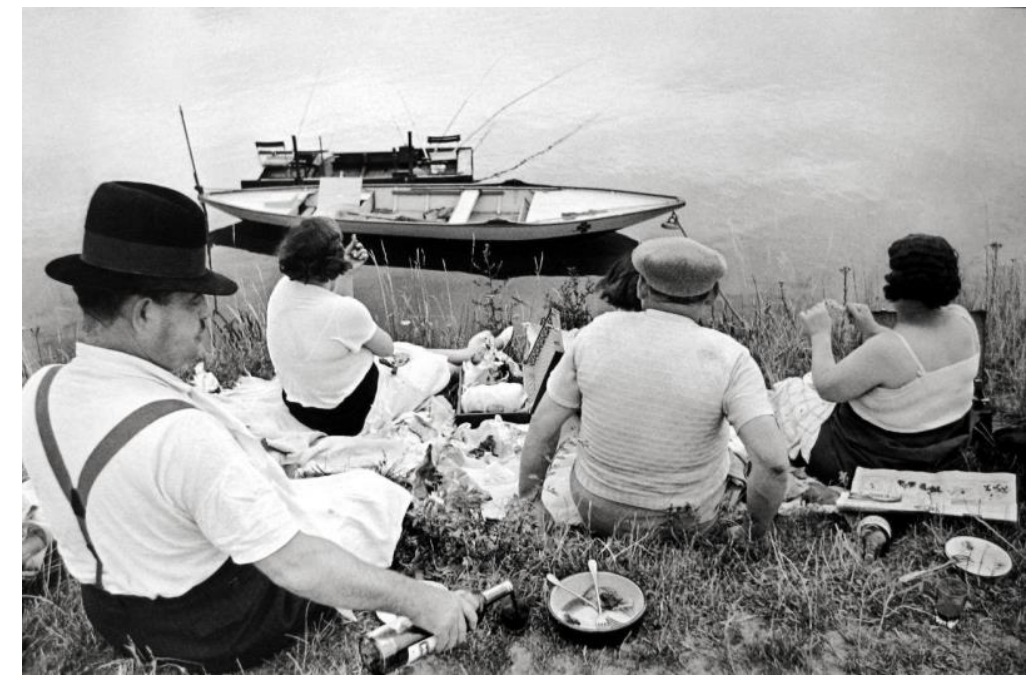

Fotografia 4. Sunday of the banks of the river Marne, 1938

Fonte: Fonte: Henri..., sd.

Como vemos na fotografia, são pessoas fazendo piquenique, observando barcos no rio. Esta foto parece remeter ao quadro Banhistas em Asnières (1984) de Georges Seurat, juntamente com a presença do barco nas obras de Monet. As saídas do meio urbano no final do século XIX com as pessoas às margens do rio, esperando com barco ao fundo. Uma foto aparentemente repleta de referências.

Por último apresentamos uma fotografia da solidão em Manhattan. 


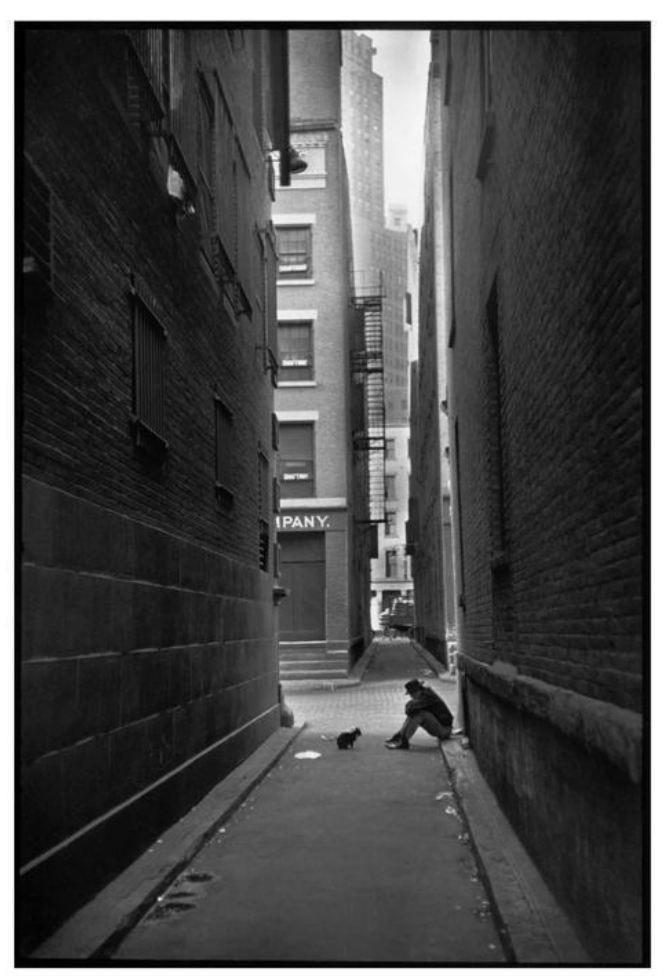

Fotografia 5. Manhattan, New York, 1968

Fonte: Fondation Henri Cartier-Bresson, 2011.

O enquadramento da foto, onde se mostram as laterais dos prédios, os prédios ao fundo, o homem ao fundo sentado e o animal à sua frente. Observa-se o desalinhamento entre a grandeza das cidades e o desolamento do ser humano frente a imensidão de seu meio. Percebemos que apesar da imensidão da cidade, o homem sente-se isolado juntamente com o animal a sua frente, se olhando. A nostalgia se mostra como um dos vários discursos presentes na fotografia, e parece ser a mensagem capturada através do instante decisivo preconizado por Bresson.

Percebemos através de alguns exemplos de fotografias de Bresson, que ela dá margem a muitas interpretações e vários discursos. Estes discursos são pessoais e dependem do olhar do expectador, do enquadramento, na percepção do instante decisivo e do grau de conhecimento que este tem inclusive sobre contextos históricos presentes no momento em que a fotografia foi tirada.

Passemos às análises sobre a indexação para as fotografias 


\section{MÉTODOS PARA INDEXAR UMA IMAGEM FOTOGRÁFICA}

Partiremos dessa prerrogativa levando em consideração que imagens serão indexadas em ambiente web, onde vemos uma crescente inserção de imagens sem técnicas, proporcionadas pelo desenvolvimento e uso cada vez maior de redes sociais e uso de redes colaborativa proporcionadas pela web 2.0. No entanto, verificamos a importância do uso de métodos de indexação para que a informação seja disponibilizada de forma a atender o usuário de forma mais satisfatória. A indexação de imagens exige técnicas diferentes da fotografia devido a distinção de seus elementos. Abordaremos, a seguir, as propostas de quatro teóricos que tratam essa representação, a fim de elencarmos a melhor forma de indexação das fotografias de Bresson, e sua eventual recuperação em um ambiente Web. Tentaremos minimizar, desta forma, as perdas pelo uso da língua na organização do conteúdo de uma imagem, utilizando esses conceitos. Descreveremos as técnicas de indexação de fotografias elaboradas por estudiosos que desenvolveram teorias que estudam os métodos de indexação de imagens e consideraremos suas contribuições na Ciência da Informação. São eles, respectivamente: Panofsky (1986), Smit (1987), Manini (2002) e Rodrigues (2007).

\subsection{Método de indexação de imagens segundo Panofsky}

Começaremos esse embasamento teórico por Panofsky (1986) e seus conceitos sobre iconografia e iconologia. Sua metodologia é baseada em três níveis de análise: descrição, identificação e compreensão da obra de arte. É importante ressaltar que Panofsky foi um historiador de arte alemão e sua proposta de análise permite uma indexação mais conotativa e subjetiva, pois foi pensada a fim de priorizar informações presentes nas artes, porém, sua forma de visualizar a problemática acabou tornando-se um referencial na área da Ciência da Informação até os dias atuais.

Consideraremos arte, portanto, a fotografia por ser uma portadora de informação e passível de análise. Os levantamentos teóricos feitos por Panofsky foram importantes, pois por meio deles, pôde-se explicar com certa clareza a importância de inserir a cultura de uma determinada sociedade nos elementos visuais que a mesma produz e, aliada a isso, há de se considerar que a investigação histórica do momento em que a produção foi elaborada tem que ser considerada. Por exemplo, uma obra de arte produzida no século XVII, estava inserida em contextos sociais que representavam, de certa forma, aquela época e não tínhamos disponíveis recursos de disseminação de informações que temos hoje em dia. Segundo Panofsky (1986) existia uma diferença entre iconografia e iconologia. Iconografia é uma forma de linguagem visual que se utiliza de imagem para representar certo tema. Iconologia, por sua vez, é o estudo do simbolismo na representação visual, ou seja, inserindo-o em um contexto.

Panofsky (1986) por meio de observações importantes sobre a análise de objetos, considerou a leitura de imagens em 3 níveis: i) Pré iconográfico: reconhecimento de um 
objeto pelo observador; ii) Iconográfico: referente a uma representação convencionada que induz a um significado reconhecível; e iii) Iconológico: significado implícita que requer imaginação do receptor ao decodificar a mensagem do emissor.

O nível Pré-Iconográfico é o lugar do tema natural ou primário (fatual e expressivo) da obra. Uma descrição pré-iconográfica permite a enumeração dos motivos artísticos do mundo das formas puras, portadoras de significados primários ou naturais.(...) O nível Iconográfico remete ao tema secundário ou convencional representado na obra: é o lugar em que se liga o motivo artístico (o tema primário ou natural) a assuntos específicos e conceitos manifestos. Este nível de análise depende diretamente do anterior, já que o reconhecimento de assuntos e conceitos pressupõe que se tenha identificado corretamente os motivos primários (MANINI apud PANOFSKY, 1986, p. 50 - 51). Finalmente o nível iconológico que por sua vez, depende exclusivamente do leitor da imagem, pois o codifica de acordo com suas experiências pessoais. É o nível onde mais o autor se afasta do expectador, pois essa leitura dependerá de aspectos individuais, incluindo sociais, culturais ideológicos e intelectuais de quem a vê.

\subsection{Método de indexação de fotografias segundo Smit}

Smit trabalha com categorias:_O que a fotografia mostra (apontando seu conteúdo informacional); Como a fotografia mostra (apontando a forma usada para mostrar tal conteúdo: a Dimensão Expressiva se enquadra nessa categoria); Onde a fotografia mostra (mostrando o documento fotográfico enquanto objeto físico).

Quanto às considerações de Shatford (apud MANINI, 2002, pag. 94-95) - O DE Genérico ocorre em primeiro plano, deverá ser feito inicialmente através de uma leitura de superfície, ou leitura rápida, identificando os elementos que constituem a imagem visualmente, também é conhecida como leitura de primeiro nível. O DE Expressivo e o SOBRE é uma análise mais minuciosa do documento, ou seja, uma leitura de profundidade. Desta forma, visa identificar os objetos que constituem a imagem de forma mais abstrata. Podemos chamar essa leitura de segundo nível, identificando os conceitos que possam ser deduzidos a partir dela. Aliado a isso, suas teorias também abordam a teoria de Panofsky e também levanta questões que respondam as perguntas que eventualmente são feitas a partir da análise da imagem fotográfica. Essas perguntas levantam questões a respeito da representação do conteúdo das imagens, e são elaboradas de forma a facilitar a interpretação de quem a vê, ou seja, embasando na importância do usuário na recuperação da imagem.

Consideremos que a utilização da Dimensão Expressiva de Smit é importante dependendo do tipo de suporte em que esta imagem será inserida. Talvez em documentos extraídos da web, não corresponda às informações mais apropriadas a serem indexadas, pois notamos variações da mesma imagem em hosts diferentes. Preconiza que é através da 
aparência física que o conteúdo informacional da fotografia se manifesta, ou seja, é a forma revelada pela técnica que faz com que a informação visual seja representada. Segundo suas pesquisas, cada unidade de informação trata a fotografia de uma forma peculiar.

De qualquer forma, a imagem retratada na fotografia, possui uma lógica, e esta lógica se manifesta no conteúdo informacional. Vimos, portanto, que os conceitos de interpretação da imagem são baseadas de forma a recuperá-la. Para ampliar essa lógica, Smit se apropria também de teorias como a de Shatford, que questiona o DE e o SOBRE, questões essas sobre a imagem. Perguntas como A IMAGEM É DE QUE? Ou A IMAGEM É SOBRE O QUE? São pertinentes para identificarmos a imagem que será analisada. Desta forma, Shatford introduz a partir desta distinção de Panofsky uma diferenciação dessa representatividade para pensar a questão da imagem e de seu conteúdo factual.

\subsection{Método de indexação de fotografias segundo Manini}

Outra autora importante na área de indexação de fotografias é Manini. Ela desenvolveu sua tese de doutorado sobre o tema "Análise documentária de fotografias: um referencial de leitura de imagens fotográficas par afins documentários” (MANINI, 2016).

Manini defende um método de representação mais completo que propõe tanto a recuperação da imagem pelo usuário levando em consideração a dimensão expressiva da fotografia proposto por Smit (1996) e insere esse método de análise na tabela. Amplia, portanto, a tabela proposta por Smit (1996) inserindo novas informações na Dimensão Expressiva da imagem, e ao contrário de Smit, a utiliza na tabela de coleta de informações. Manini (2002) defende que a coleta de informações utilizando a técnica, a fim de incluir também o conteúdo em fotografias digitais, conservando suas peculiaridades. De certa forma, Manini (2002), acredita que a partir do tratamento da imagem pelo profissional da informação, entramos em um outro patamar, substituindo o documento original, por algo que o transcreva. Leva em consideração o fato da imagem já processada e disponibilizada em algum acervo disponibilizando assim, sua recuperação. Desta forma, desvia o foco do fotógrafo para o usuário, pois este é quem traduzirá esta mensagem. Sobre a Dimensão expressiva de Smit (1986), Manini propõe algumas alterações para que a análise de imagem se torne mais completa, e desta forma, pode-se inclusive fazer uma análise, segundo o conceito, de imagens digitais. Segue proposta no quadro a seguir, já incluindo suas complementações:

Quadro 1. A Dimensão Expressiva segundo Manini

\begin{tabular}{|c|c|}
\hline RECURSOS TÉCNICOS & VARIÁVEIS \\
\hline Efeitos Especiais & $\begin{array}{c}\text { Fotomontagem/estroboscopia/altocontraste/trucagens/esfum } \\
\text { ação/etc. }\end{array}$ \\
\hline Ótica & Utilização de objetivas (fish-eye, lente normal, grande- \\
\hline
\end{tabular}




\begin{tabular}{|c|c|}
\hline & $\begin{array}{c}\text { angular, teleobjetiva, etc.) /utilização de filtros } \\
\text { (infravermelho) /ultravioleta / etc }\end{array}$ \\
\hline Tempo de Exposição & Instantâneo/pose/longa exposição/etc \\
\hline Luminosidade & Luz diurnal/luz noturna/contraluz/luz artificial/etc \\
\hline Enquadramento & $\begin{array}{c}\text { Enquadramento do objeto fotografado (vista parcial, vista } \\
\text { geral, etc.) - Enquadramento de seres vivos (plano geral, } \\
\text { médio, americano, close, detalhe)/etc }\end{array}$ \\
\hline Posição da Câmera & $\begin{array}{c}\text { Câmara alta/câmara baixa/vista aérea/vista submarina/vista } \\
\text { subterrânea/microfotografia eletrônica/distância focal } \\
\text { (fotógrafo/objeto)/etc. }\end{array}$ \\
\hline Composição & Retrato/paisagem/natureza morta/etc. \\
\hline Profundidade de Campo & $\begin{array}{c}\text { Com profundidade: todos os campos fotográficos nítidos } \\
\text { (diafragma mais fechado) - Sem profundidade: o campo de } \\
\text { fundo sem nitidez (diafragma mais aberto) }\end{array}$ \\
\hline
\end{tabular}

Fonte: Manini, 2002.

\subsection{Método de indexação de fotografias segundo Rodrigues}

Rodrigues (2007), assim como Manini (2002), Smit(1987) e Panofsky (1986), também busca por uma metodologia que atenda a necessidade relativa à indexação de imagens fotográficas, porém com um foco voltado à tematização dos elementos contidos na fotografia. Para ele, indexar uma fotografia é diferente de tematizá-la, e essa tematização deve ser a base do conceito. Para Rodrigues, “(...) a tematização de uma imagem não deve ser confundida com a indexação ou classificação dessa imagem. Uma foto de uma criança chorando sozinha numa praia, por exemplo, pode ser indexada por CRIANÇA, CHORO, PRAIA, MAR etc.”. A mesma foto pode ser contextualizada (tematizada) para ilustrar temas como CRIANÇAS ABANDONADAS, FOME, etc.

Verificamos, desta forma, uma sutil diferença entre os dois termos. Quando indexamos, descrevemos basicamente aquilo que estamos vendo na imagem afim de representa-la. Quando tematizamos, inserimos no referente, um contexto que não está objetivamente ligado a ele, ou seja, um elemento denotativo que não necessariamente está representado. Utilizando o exemplo da citação do próprio autor, o termo $\mathrm{CHORO}$, foi indexado de forma a traduzir a imagem. Se utilizássemos por exemplo, o termo TRISTEZA, apesar de não tematizá-la, utilizaríamos de uma interpretação através de um sentido conotativo identificado e atribuído à imagem.

$\mathrm{O}$ autor estabelece que existem outras características relevantes a serem consideradas além da tematização, conforme prevê (RODRIGUES, 2007 p.75):

a) Descrições físicas: Autor, descrições físicas dos componentes da imagem, tamanho e formato da imagem fotográfica, tipo de suporte, transformações da imagem a partir da original, etc); 
b) Composição: Tipo de luz, ponto de vista do fotógrafo, filtros, nitidez, profundidade, enquadramento, etc);

c) Contexto arquivistico: locais e períodos históricos correspondentes à fotografia, relações com fatos ou documentos;

d) Sentido denotativo: O que a imagem contém ou mostra;

e) Sentido conotativo: Descrição dos sentidos concretos ou abstratos que a foto pode trazer;

f) Tematização: Descrição dos sentidos.

\section{INDEXAÇÃO DE IMAGENS UTILIZANDO AS METODOLOGIAS}

Percebemos no decorrer do trabalho, que cada tipo de imagem possui particularidades, e desta forma, não existe um consenso no que se refere à padronização das mesmas. A indexação de uma pintura, por exemplo, é diferente de uma fotografia na sua forma e conteúdo. Desta forma, torna-se impraticável classificar uma metodologia que se encaixe à todo tipo de imagem que nós profissionais da informação, iremos nos deparar. Tudo é muito relativo no que se refere à conceituação de documentos imagéticos. Resolvemos portanto, fazer uma experimentação das quatro técnicas apresentadas no trabalho e verificar de forma prática, a que mais se encaixa no perfil de indexação proposto por Cartier-Bresson e seu termo "instante decisivo". Com relação à fotografia 03 referente à Gare St Lazare, Paris, 1932, temos

Quadro 2. Indexação na tabela de Panofsky para fotografia 1

\begin{tabular}{|c|c|c|}
\hline Pré-iconográfico & Iconográfico & Iconológico \\
\hline Homem & & Sincronia \\
Sombra & Simetria & Harmonia \\
Escada & & Geometria \\
Reflexo & Fluidez \\
Cerca & & \\
\hline
\end{tabular}

Fonte: Elaborado pelos autores 
Quadro 3. Indexação na tabela de Smit para fotografia 1

\begin{tabular}{|c|c|c|c|}
\hline & \multicolumn{2}{|c|}{ DE } & \multirow[b]{2}{*}{ SOBRE } \\
\hline Categoria & Genérico & Específico & \\
\hline Quem/O Que & $\begin{array}{l}\text { Homem } \\
\text { Escada } \\
\text { Reflexos }\end{array}$ & & \multirow{4}{*}{ Reflexos } \\
\hline Onde & & França & \\
\hline Quando & & 1932 & \\
\hline Como & & $\begin{array}{c}\text { Atravessando uma } \\
\text { rua/lago }\end{array}$ & \\
\hline
\end{tabular}

Fonte: Elaborado pelos autores

Quadro 4. Indexação na tabela de Manini para fotografia 1

\begin{tabular}{|c|c|c|c|c|}
\hline \multirow[b]{3}{*}{ Categoria } & \multicolumn{3}{|c|}{ Conteúdo Informacional } & \multirow[b]{2}{*}{ Dimensão Expressiva } \\
\hline & \multicolumn{2}{|c|}{ DE } & SOBRE & \\
\hline & Genérico & Específico & \multirow{5}{*}{ Reflexos } & \multirow{5}{*}{$\begin{array}{c}\text { Retrato } \\
\text { Plano Geral }\end{array}$} \\
\hline Quem/O Que & $\begin{array}{c}\text { Homem } \\
\text { Escada } \\
\text { Reflexos }\end{array}$ & & & \\
\hline Onde & & França & & \\
\hline Quando & & 1932 & & \\
\hline Como & & $\begin{array}{c}\text { Atravessando } \\
\text { uma rua } \\
\text { alagada/lago }\end{array}$ & & \\
\hline
\end{tabular}

Fonte: Elaborado pelos autores

Quadro 5. Indexação na tabela de Rodrigues para fotografia 1

\begin{tabular}{|c|c|c|c|c|c|}
\hline $\begin{array}{l}\text { Descrição } \\
\text { Física }\end{array}$ & $\begin{array}{l}\text { Composiçã } \\
\text { o }\end{array}$ & $\begin{array}{c}\text { Contexto } \\
\text { Arquivístico }\end{array}$ & $\begin{array}{c}\text { Sentido } \\
\text { Denotativo }\end{array}$ & $\begin{array}{c}\text { Sentido } \\
\text { Conotativo }\end{array}$ & Tematização \\
\hline $\begin{array}{c}\text { Cartier- } \\
\text { Bresson/Web }\end{array}$ & $\begin{array}{l}\text { Preto / } \\
\text { Branco }\end{array}$ & $\begin{array}{l}1932 / \\
\text { França }\end{array}$ & $\begin{array}{c}\text { Homem / } \\
\text { Expectador / } \\
\text { Escada / } \\
\text { Reflexo / } \\
\text { Cerca / Rua } \\
\text { /Alagada } \\
\text { /Lago }\end{array}$ & $\begin{array}{c}\text { Sincronia / } \\
\text { Harmonia } \\
\text { /Geometria / } \\
\text { Fluidez }\end{array}$ & $\begin{array}{c}\text { Fusão / Dança } \\
\text { / Profusão / } \\
\text { Fuga / } \\
\text { Levitação }\end{array}$ \\
\hline
\end{tabular}

Fonte: Elaborado pelos autores 
Com relação à fotografia de numero 04 referente ao piquenique na beira do rio, temos os seguintes indicativos de indexação:

Quadro 6. Indexação na tabela de Panofsky para fotografia 4

\begin{tabular}{|c|c|c|}
\hline Pré-Iconográfico & Iconográfico & Iconológico \\
\hline Barco & & Arte \\
Pessoas & & Monet \\
Piquenique & Espera & Pessoas confraternizando e \\
Vara de pesca & & \\
Comida & & \\
Bebida & & \\
Rio & & \\
\hline
\end{tabular}

Fonte: Elaborado pelos autores

Quadro 7. Indexação na tabela de Smit para fotografia 4

\begin{tabular}{|c|c|c|c|}
\cline { 2 - 3 } \multicolumn{1}{c|}{ Categoria } & Genérico & Específico & \multirow{2}{*}{ SOBRE } \\
\hline Quem/O Que & $\begin{array}{c}\text { Pessoas } \\
\text { Barco }\end{array}$ & Pessoas confraternizando & \multirow{2}{*}{ Piquenique } \\
\hline Onde & Beira do rio & Rio Marne & \\
\hline Quando & Confraternização & $\begin{array}{c}\text { Pessoas fazendo } \\
\text { piquenique às margens } \\
\text { do rio Marne com barco } \\
\text { ao fundo }\end{array}$ & \\
\hline Como & $\begin{array}{c}1938 \\
\end{array}$
\end{tabular}

Fonte: Elaborado pelos autores 
Quadro 8. Indexação na tabela de Manini para fotografia 4

\begin{tabular}{|c|c|c|c|c|}
\hline \multirow[b]{3}{*}{ Categoria } & \multicolumn{3}{|c|}{ Conteúdo Informacional } & \multirow[b]{2}{*}{ Dimensão Expressiva } \\
\hline & \multicolumn{2}{|r|}{ DE } & SOBRE & \\
\hline & Genérico & Específico & \multirow{5}{*}{ Piquenique } & \multirow{5}{*}{$\begin{array}{c}\text { Retrato } \\
\text { Plano Geral } \\
\text { Vista geral }\end{array}$} \\
\hline Quem/O Que & $\begin{array}{c}\text { Pessoas } \\
\text { Barco }\end{array}$ & $\begin{array}{c}\text { Pessoas } \\
\text { confraternizando }\end{array}$ & & \\
\hline Onde & Beira do rio & Beira do rio & & \\
\hline Quando & & 1938 & & \\
\hline Como & $\begin{array}{c}\text { Confraterniz } \\
\text { ação }\end{array}$ & $\begin{array}{c}\text { Pessoas fazendo } \\
\text { piquenique às } \\
\text { margens do rio } \\
\text { Marne com barco ao } \\
\text { fundo }\end{array}$ & & \\
\hline
\end{tabular}

Fonte: Elaborado pelos autores

Quadro 9. Indexação na tabela de Rodrigues para fotografia 4

\begin{tabular}{|c|c|c|c|c|c|}
\hline $\begin{array}{l}\text { Descrição } \\
\text { Física }\end{array}$ & Composição & $\begin{array}{c}\text { Contexto } \\
\text { Arquivístico }\end{array}$ & $\begin{array}{c}\text { Sentido } \\
\text { Denotativo }\end{array}$ & $\begin{array}{c}\text { Sentido } \\
\text { Conotativo }\end{array}$ & Tematização \\
\hline $\begin{array}{c}\text { Cartier-Bresson } \\
\text { Web }\end{array}$ & $\begin{array}{l}\text { Preto e } \\
\text { branco }\end{array}$ & $\begin{array}{l}\text { Rio Marne } \\
1938\end{array}$ & $\begin{array}{c}\text { Barco } \\
\text { Pessoas } \\
\text { Piquenique } \\
\text { Vara de } \\
\text { pesca } \\
\text { Comida } \\
\text { Bebida }\end{array}$ & $\begin{array}{c}\text { Arte } \\
\text { Monet } \\
\text { Pessoas } \\
\text { confraternizando } \\
\text { e observando o } \\
\text { barco no rio }\end{array}$ & $\begin{array}{l}\text { Busca de } \\
\text { afetos } \\
\text { Resgate das } \\
\text { emoções }\end{array}$ \\
\hline
\end{tabular}

Fonte: Elaborado pelos autores

A fotografia da solidão em Manhattan apresentada aqui como a de número 05 teria o seu processo de indexação da seguinte foram:

Quadro 10. Indexação na tabela de Panofsky para fotografia 5

\begin{tabular}{|c|c|c|}
\hline Pré-Iconográfico & Iconográfico & Iconológico \\
\hline Prédios & Nostalgia \\
Homem Sentado & Solidão & Vazio \\
Animal & & Ausência \\
Ruas & & Finitude \\
\hline
\end{tabular}

Fonte: Elaborado pelos autores 
Quadro 11. Indexação na tabela de Smit para fotografia 5

\begin{tabular}{|c|c|c|c|}
\hline & \multicolumn{2}{|c|}{ DE } & \multirow[b]{2}{*}{ SOBRE } \\
\hline Categoria & Genérico & Específico & \\
\hline Quem/O Que & $\begin{array}{c}\text { Homem / Animal / } \\
\text { Prédios }\end{array}$ & & \\
\hline Onde & & New York & \\
\hline Quando & & 1968 & \\
\hline Como & & $\begin{array}{c}\text { Homem sentado na } \\
\text { sarjeta em uma cidade } \\
\text { grande, sob a } \\
\text { observação de um } \\
\text { animal de pequeno porte } \\
\text { e prédios ao redor }\end{array}$ & Solidão \\
\hline
\end{tabular}

Fonte: Elaborado pelos autores

Quadro 12. Indexação na tabela de Manini para fotografia 5

\begin{tabular}{|c|c|c|c|c|}
\hline \multirow[b]{3}{*}{ Categoria } & \multicolumn{3}{|c|}{ Conteúdo Informacional } & \multirow[b]{2}{*}{ Dimensão Expressiva } \\
\hline & \multicolumn{2}{|c|}{ DE } & SOBRE & \\
\hline & Genérico & Específico & & \\
\hline Quem/O Que & $\begin{array}{c}\text { Homem / } \\
\text { Animal }\end{array}$ & & & \\
\hline Onde & & New York & & \\
\hline Quando & & 1968 & & \\
\hline Como & & $\begin{array}{c}\text { Homem } \\
\text { sentado na } \\
\text { sarjeta em uma } \\
\text { cidade grande, } \\
\text { sob a } \\
\text { observação de } \\
\text { um animal de } \\
\text { pequeno porte } \\
\text { e prédios ao } \\
\text { redor }\end{array}$ & Solidão & $\begin{array}{c}\text { Retrato } \\
\text { Plano Geral }\end{array}$ \\
\hline
\end{tabular}


Fonte: Elaborado pelos autores

Quadro 13. Indexação na tabela de Rodrigues para fotografia 5

\begin{tabular}{|c|c|c|c|c|c|}
\hline $\begin{array}{c}\text { Descrição } \\
\text { Física } \\
\end{array}$ & Composição & $\begin{array}{c}\text { Contexto } \\
\text { Arquivístico } \\
\end{array}$ & $\begin{array}{c}\text { Sentido } \\
\text { Denotativo }\end{array}$ & $\begin{array}{c}\text { Sentido } \\
\text { Conotativo }\end{array}$ & Tematização \\
\hline $\begin{array}{c}\text { Cartier- } \\
\text { Bresson } \\
\text { Web }\end{array}$ & $\begin{array}{l}\text { Preto e } \\
\text { Branco }\end{array}$ & $\begin{array}{c}\text { New York } \\
1968\end{array}$ & $\begin{array}{c}\text { Prédios } \\
\text { Homem Sentado } \\
\text { Animal } \\
\text { Ruas }\end{array}$ & $\begin{array}{l}\text { Solidão } \\
\text { Nostalgia } \\
\text { Vazio }\end{array}$ & $\begin{array}{l}\text { Ausência de } \\
\text { cores e } \\
\text { elementos } \\
\text { Ausência de } \\
\text { sentimentos } \\
\text { Nostalgia }\end{array}$ \\
\hline
\end{tabular}

Fonte: Elaborado pelos autores

\section{CONCLUSÃ̃}

Avaliando as metodologias é possível verificar uma grande diferença entre elas, principalmente no que ser refere à inserção de informações ligadas à leitura das fotografias.

Algumas baseiam seu processo de análise documental em termos mais técnicos, como é o caso de Smit (1996) e Manini (2002), outras formas de análise, abrem um leque de opções de termos de indexação que propiciam uma abordagem mais conotativa, com é o caso de Panofsky e Rodrigues. É possível observar que algumas lacunas não são preenchidas, devido ao fato de serem imagens capturadas via web e, portanto, não possuírem informações mais completas a respeito da obra a ser indexada, outra observação importante é o tipo de obra que está sendo analisado, no caso as fotografias de Henri Cartier-Bresson, que possui uma carga subjetiva mais "abrangente", através do seu conceito de Instante Decisivo.

Algumas informações que utilizamos para inserir nas tabelas, só foram possíveis conforme a legenda que as mesmas apresentavam. A imagem em si não carregava esta informação. No entanto é importante observarmos que todas as formas de análise experimentadas, tem sua relevância no que ser refere à descrição dos itens dispostos.

Especificamente nas obras de Cartier-Bresson, acreditamos que os métodos mais indicados são exatamente os que possibilitam a descrição de elementos implícitos à imagem, ou seja, os métodos sugeridos por Panofsky (1986) e Rodrigues (2007). Contudo, observamos que a metodologia proposta por Panofsky (1986) aborda elementos mais simplistas e que eventualmente foram aprimoradas por outros teóricos, como Rodrigues, e também, apesar de um outro olhar referente à importância de elementos à serem indexados, também Manini(2002) e Smit (1996). 
Alguns aspectos a serem considerados, segundo as metodologias de Manini (2002) e Smit (1996), não são incorporadas nas obras analisadas de Bresson, principalmente pelo fato dessas imagens serem capturadas via internet, e por esse motivo, não possuíam informações técnicas suficientes para o preenchimento completo da tabela, como por exemplo, proporções, questões ligadas a luminosidade, profundidade de campo, composição, enquadramento, etc.

Apesar das complementações feitas por Manini (2002), sobre a dimensão expressiva, na proposta de Smit (1996), acreditamos que a análise documentária proposta pelo profissional da informação, será uma reconstrução do que está sendo indexado também sob o ponto de vista do fotógrafo. Concluímos que de acordo com as metodologias experimentadas, a de Rodrigues é a que mais se encaixa no perfil do objeto analisado, justamente por comportar de forma mais ampla os sentidos implícitos.

Nós como profissionais da informação, tratamos as informações contidas na imagem também como mediadores, e por esse motivo evidencia a necessidade de nos colocarmos entre os dois extremos: o do fotógrafo e o usuário.

\section{REFERÊNCIAS}

BAZIN, Andre. Ontologia da imagem fotográfica. In. XAVIER, Ismail (Org.) A existência do cinema. Rio de Janeiro: Edições Graal, 1991.

CARTIER-BRESSON, Henri. O instante decisivo. In. BACELLAR, Mario Clark (Org).

Fotografia e Jornalismo. São Paulo: Escola de Comunicações e Artes (USP), 1971, p. 19-26.

CARTIER-BRESSON, Henri. O imaginário segundo a natureza. São Paulo: GG Brasil, 2004.

CHALHUB, Samira. A metalinguagem. São Paulo: Ática, 2002.

FONDATION HENRI CARTIER-BRESSON. Henri Cartier-Bresson (1908-2004). Paris: [s.1.], 2011. Disponível em: < http://www.christies.com/lotfinder/Lot/henri-cartier-bresson-1908-2004downtown-manhattan-new-5494251-details.aspx >. Acesso em: 15 abril 2017.

HENRI Cartier-Bresson. Galeria. Fotografia e Fotógrafos. s.d. Disponível em: < http://galeria.obviousmag.org/fotografia/bresson/page/3 >. Acesso em: 15 abril 2017.

KOSSOY, Boris. Fotografia e História. São Paulo: Ateliê Editorial, 2001.

KOSSOY, Boris. Realidades e ficções na trama fotográfica. São Paulo: Ateliê Editorial, 1999.

LE GOFF, Jacques. História e memória. E. ed. Campinas: Ed. Unicamp, 2003.

MANINI, Miriam Paula. Análise documentária de fotografias: um referencial de leitura de imagens fotográficas para fins documentários. São Paulo, 2002. Tese (doutorado) - Escola de Comunicações e Artes, USP. 
MANINI, Miriam Paula. Aspectos informacionais do tratamento de documentos fotográficos tradicionais e digitais. Brasília, 2009. Disponível em: < http://enancib.ibict.br/index.php/enancib/ xenancib/paper/viewFile/3156/2282/>. Acesso em: 22 agosto de 2016.

MICHAELIS: Dicionário Brasileiro da Língua Portuguesa. São Paulo: Editora Melhoramentos, 2015. Disponível em: < http://michaelis.uol.com.br/busca? $\mathrm{r}=\& \mathrm{f}=\& \mathrm{t}=\&$ palavra $=$ memória $>$. Acesso em: 17 mar 2017.

MOREIRA, Mirian. Retratos de Família, leitura da fotografia histórica. São Paulo, Editora da Universidade de São Paulo, 1993.

PANOFSKY, Erwin. Iconografia e Iconologia: Uma introdução ao estudo da arte da Renascença. In: Significado nas Artes Visuais. Tradução: Maria Clara F. Kneese e J. Guinsburg. São Paulo: Perspectiva, 2.ed. 1986, p. 47-65.

RODRIGUES, Ricardo Crisafulli. Análise e tematização da imagem fotográfica. 2007. CI. Inf., Brasilia, v. 36, n.36, n.3, p.67-76, set./dez.2007.

SANTANA, Lucia. INFOESCOLA (São Paulo, SP). A fotografia de Henri Cartier-Bresson. Artes. 2016. Disponível em: <http://www.infoescola.com/artes/a-fotografia-de-henri-cartierbresson/>. Acesso em: 27 junho 2016.

SMIT, Johanna W. Análise da imagem: Um primeiro plano. In. SMIT, Johanna W. (coord.). Análise documentária: Análise da Síntese. Brasília: IBICT, 1987. Cap. 6

SMIT, Johanna Wilhelmina. A representação da imagem. INFORMARE - cad. Prog. Pósgrad. Ci. Inf., Rio de Janeiro, v.2, n.2, p. 28-36, jul./dez.1996.

SMIT, Johanna Wilhelmina. Propostas para a indexação de informação iconográfica, 1997b. (Mimeo).

SONTAG, Susan. Ensaios sobre a fotografia. Trad. Joaquim Paiva. Rio de Janeiro, Arbor, 1981.
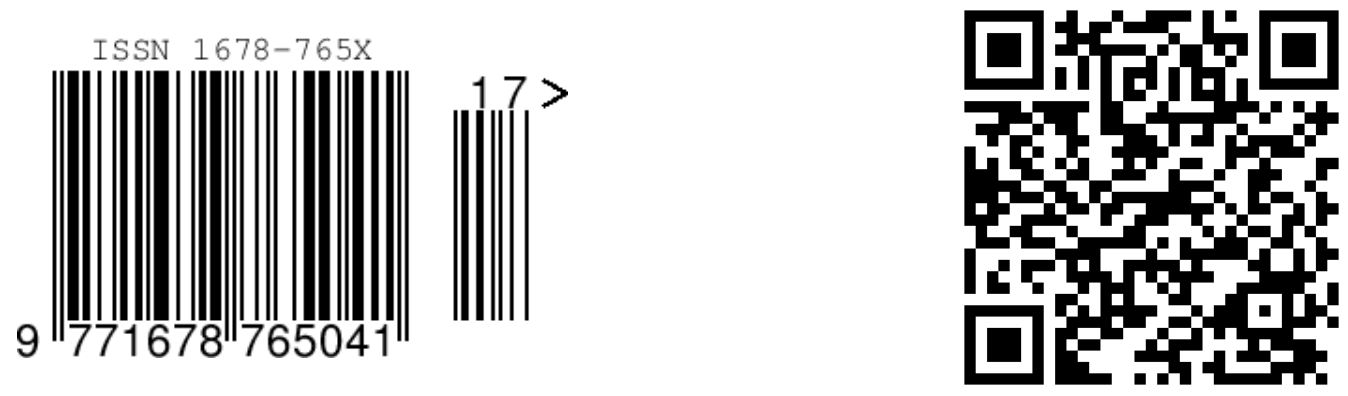